\title{
Increased prothrombotic state lasting as long as one month after on-pump and off-pump coronary surgery
}

\author{
Alessandro Parolari, MD, $\mathrm{PhD},{ }^{a}$ Luciana Mussoni, $\mathrm{PhD},{ }^{\mathrm{c}}$ Marta Frigerio, $\mathrm{PhD},{ }^{a}$ Moreno Naliato, $\mathrm{MD},{ }^{a}$ \\ Francesco Alamanni, MD, ${ }^{a}$ Andrea Galanti, MD, ${ }^{a}$ Giuseppe Fiore, MD, ${ }^{a}$ Fabrizio Veglia, PhD, ${ }^{b}$ Elena Tremoli, PhD, \\ Paolo Biglioli, MD, and Marina Camera, Biol Sci, PhD ${ }^{\mathrm{a}, \mathrm{c}}$
}

From the Department of Cardiac Surgery ${ }^{\mathrm{a}}$ and the Biostatistics Unit, ${ }^{\mathrm{b}}$ Centro Cardiologico Monzino IRCCS, and the Department of Pharmacological Sciences, ${ }^{c}$ University of Milan, Milan, Italy.

Supported by the Italian Ministry of Health (RF 2002 convenzione No. 191).

Received for publication July 12, 2004; revisions received Oct 27, 2004; accepted for publication Nov 2, 2004.

Address for reprints: Alessandro Parolari, MD, PhD, Department of Cardiac Surgery, University of Milan, Centro Cardiologico Fondazione Monzino IRCCS, Via Parea, 4, 20138, Milan, Italy (E-mail: alessandro. parolari@cardiologicomonzino.it).

J Thorac Cardiovasc Surg 2005;130:303-8

$0022-5223 / \$ 30.00$

Copyright (c) 2005 by The American Association for Thoracic Surgery

doi:10.1016/j.jtcvs.2004.11.002
Objective: This study investigated whether the activation of coagulation, fibrinolysis, and endothelium occurring during the first postoperative month after on-pump coronary artery bypass surgery differs from that after off-pump coronary artery bypass grafting.

Methods: Thirty-five patients candidates to coronary surgery were randomized to undergo on-pump $(n=18)$ or off-pump $(n=17)$ coronary artery bypass grafting. Blood samples were collected before the intervention and to 1 month after surgery.

Results: Prothrombin fragment F1.2, thrombin-antithrombin complex, and D-dimer increased after surgery and were persistently higher than preoperative values as late as 30 postoperative days in both on- and off-pump groups; higher levels of these variables were detected after on-pump surgery relative to off-pump surgery only at the time point after termination of cardiopulmonary bypass (fragment F1.2 and thrombin-antithrombin complex) or from bypass end to 8 postoperative days (Ddimer). Fibrinogen levels decreased after surgery and then increased in parallel in both groups to 8 days after surgery. The von Willebrand factor level increased postoperatively in both groups and returned to baseline 30 days after surgery; it was higher after on-pump surgery from bypass end to 8 postoperative days. Soluble vascular cell adhesion molecule 1 was increased significantly from baseline in both groups 30 days after surgery, with no difference between groups.

Conclusion: Patients undergoing off-pump surgery showed protection against activation of coagulation and fibrinolysis and against endothelial injury only during the intraoperative period; this was followed by the development of a prothrombotic pattern comparable to that of patients undergoing on-pump surgery lasting at least as late as 30 days after surgery.

$\mathrm{S}$ tudies, mainly performed in patients undergoing coronary artery bypass grafting $(\mathrm{CABG})$, have shown that cardiopulmonary bypass $(\mathrm{CPB})$ use is associated with activation of several metabolic pathways and cellular components leading to a systemic inflammatory response. ${ }^{1}$ This response has mainly been documented to occur in the early hours after surgery, but some studies have shown a marked activation of the hemostatic, thrombotic, and inflammatory systems to persist for several weeks after coronary surgery. ${ }^{2-5}$

During the past decade, several technical advances have allowed the reintroduction into clinical practice of $C A B G$ performed on a beating heart without $\mathrm{CPB}$ (OPCAB). OPCAB has been proposed as a surgical strategy that by avoiding CPB would extensively reduce postoperative inflammatory response. ${ }^{6}$ It is therefore expected that patients undergoing $\mathrm{OPCAB}$ would experience fewer postoperative adverse events.

The clinical advantage of OPCAB versus standard on-pump CABG is, however, still debated. ${ }^{7,8}$ It is also unclear whether CPB is the main cause of the postoperative inflammatory and procoagulant responses that occur after cardiac surgery; recently, 
TABLE 1. Clinical variables in the study population

\begin{tabular}{|c|c|c|c|}
\hline Variable & CABG $(n=18)$ & OPCAB (n = 15) & $P$ value \\
\hline Age $(y$, mean \pm SEM) & $62 \pm 2.3$ & $62 \pm 2.4$ & .71 \\
\hline Male sex (No.) & $8(44 \%)$ & $8(53 \%)$ & $>.99$ \\
\hline Previous myocardial infarction (No.) & $7(50 \%)$ & $7(64 \%)$ & .61 \\
\hline Type 1 diabetes (No.) & $1(6 \%)$ & $0(0 \%)$ & $>.99$ \\
\hline Type 2 diabetes (No.) & $4(22 \%)$ & $0(0 \%)$ & .11 \\
\hline Chronic obstructive pulmonary disease (No.) & $5(28 \%)$ & $4(27 \%)$ & $>.99$ \\
\hline Hypertension (No.) & $11(61 \%)$ & $10(67 \%)$ & .97 \\
\hline Echocardiographic ejection fraction $(\%$, mean \pm SEM) & $59 \% \pm 2.7 \%$ & $56 \% \pm 2.2 \%$ & .33 \\
\hline Total cholesterol (mg/dL, mean \pm SEM) & $204 \pm 11$ & $226 \pm 14$ & .18 \\
\hline Low-density lipoprotein cholesterol (mg/dL mean \pm SEM) & $137 \pm 11$ & $145 \pm 13$ & .63 \\
\hline High-density lipoprotein cholesterol (mg/dL, mean \pm SEM) & $43 \pm 3.1$ & $46 \pm 3.1$ & .45 \\
\hline Plasma triglycerides $(\mathrm{mg} / \mathrm{dL}$, mean \pm SEM) & $158 \pm 36$ & $196 \pm 43$ & .50 \\
\hline Preoperative hematocrit $(\%$, mean \pm SEM) & $42 \% \pm 0.6 \%$ & $44 \% \pm 1.2 \%$ & .26 \\
\hline Diseased coronary vessels (mean \pm SEM) & $3 \pm 0$ & $2.7 \pm 0.15$ & .34 \\
\hline Distal anastomoses (mean \pm SEM) & $3.1 \pm 0.18$ & $2.9 \pm 0.26$ & .46 \\
\hline Distal left internal thoracic artery anastomoses (mean \pm SEM) & $1.1 \pm 0.05$ & $1.3 \pm 0.13$ & .18 \\
\hline Distal saphenous vein anastomoses (mean \pm SEM) & $1.6 \pm 0.20$ & $1.1 \pm 0.22$ & .15 \\
\hline Distal radial artery anastomoses (mean \pm SEM) & $0.4 \pm 0.15$ & $0.4 \pm 0.13$ & .96 \\
\hline CPB time (min, mean \pm SEM) & $119 \pm 6.3$ & - & - \\
\hline Crossclamp time (min, mean \pm SEM) & $81 \pm 4.6$ & - & - \\
\hline 2-h bleeding ( $\mathrm{mL}$, mean \pm SEM) & $154 \pm 21$ & $141 \pm 15$ & .95 \\
\hline 24-h bleeding (mL, mean \pm SEM) & $628 \pm 58$ & $573 \pm 36$ & .49 \\
\hline Total bleeding $(\mathrm{mL}$, mean $\pm \mathrm{SEM})$ & $701 \pm 66$ & $615 \pm 36$ & .37 \\
\hline Ventilation time (h, mean \pm SEM) & $5.4 \pm 0.51$ & $5.0 \pm 0.50$ & .56 \\
\hline Transfused patients (No.) & $3 / 18(17 \%)$ & $1 / 15(6.7 \%)$ & .61 \\
\hline Transfused blood (U, mean \pm SEM) & $0.6 \pm 0.35$ & $0.3 \pm 0.27$ & .34 \\
\hline
\end{tabular}

it has been hypothesized that surgical trauma, in addition to $\mathrm{CPB}$, may cause activation of inflammatory and coagulation-fibrinolytic pathways. $^{9}$

We therefore investigated whether activation of coagulation and fibrinolysis differed between patients undergoing OPCAB and CABG at the end of surgery. Because graft occlusion mainly occurs during the first month after the surgical intervention, the same thrombotic variables were also assessed to 1 month after surgery.

\section{Patients and Methods \\ Patients}

Thirty-five patients were consecutively enrolled among those candidates to elective surgical myocardial revascularization according to the American Heart Association and American College of Cardiology guidelines ${ }^{10}$ and were randomly assigned to undergo OPCAB $(n=17)$ or CABG $(n=18)$. In all cases, the preoperative ejection fraction was greater than $30 \%$, and the left ventricular end-diastolic pressure was below $20 \mathrm{~mm} \mathrm{Hg}$. Preoperative exclusion criteria were age older than 80 years, renal or liver disease, and intake of drugs affecting platelet function or coagulation or fibrinolysis within 10 days before surgery. Intraoperative and postoperative exclusion criteria were excessive $(>1000 \mathrm{~mL} / \mathrm{d})$ postoperative bleeding or reexploration for bleeding, perioperative myocardial infarction, stroke, and renal failure requiring dialysis.
All patients gave informed consent to participate in this study, which was approved by the Ethical Committee of Centro Cardiologico Monzino I.R.C.C.S. All patient care has been managed by the same surgical and anesthesiologic team.

\section{Anesthesia}

Patient care management during and after surgery was the same for both groups of patients. All patients continued their cardiac medications until surgery. Anesthetic premedication was atropine (0.5 $\mathrm{mg})$ and morphine sulfate $(0.1 \mathrm{mg} / \mathrm{kg})$ given intramuscularly 1 hour before surgery.

Anesthesia was then induced by the administration of sodium thiopental $(4-5 \mathrm{mg} / \mathrm{kg})$, fentanyl $(100 \mu \mathrm{g})$, succinylcholine (INN: suxamethonium, $1 \mathrm{mg} / \mathrm{kg})$, and pancuronium bromide $(0.1 \mathrm{mg} / \mathrm{kg})$. After the induction of anesthesia, all patients underwent orotracheal intubation. Cefuroxime ( $2 \mathrm{~g}$ ) was given intravenously for infection prophylaxis. A continuous infusion of propofol was started after anesthesia induction $(3-4 \mathrm{mg} /[\mathrm{kg} \cdot \mathrm{h}])$, and boluses of sufentanil (25 $\mu \mathrm{g}$ for a maximum total dose of $0.3 \mathrm{mg}$ ) and pancuronium bromide ( $2 \mathrm{mg}$ ) were given when necessary.

After internal thoracic artery takedown, systemic heparinization (300 IU/kg bovine lung heparin) was administered, and activated clotting time was kept to at least 440 seconds with additional heparin in both groups. On completion of distal and proximal coronary anastomoses, heparin was antagonized with protamine sulfate at a $1: 1$ ratio $(3 \mathrm{mg} / \mathrm{kg})$ in both groups. 
TABLE 2. Measured plasma constituents with time

\begin{tabular}{|c|c|c|c|c|c|c|c|c|}
\hline \multirow[b]{2}{*}{ Variable } & \multirow[b]{2}{*}{ Baseline } & \multirow[b]{2}{*}{ Protamine } & \multirow[b]{2}{*}{$4 \mathrm{~d}$} & \multirow[b]{2}{*}{$8 \mathrm{~d}$} & \multirow[b]{2}{*}{$30 \mathrm{~d}$} & \multicolumn{3}{|c|}{ Main effects ANCOVA } \\
\hline & & & & & & Time & Treatment & Interaction \\
\hline \multicolumn{6}{|c|}{ TAT $(\mathrm{ng} / \mathrm{mL}$, mean $\pm \mathrm{SEM})$} & $<.0001$ & .0002 & $<.0001$ \\
\hline CABG & $3.1 \pm 0.39$ & $92.9 \pm 9.52^{*} \dagger$ & $19.6 \pm 3.68^{*}$ & $18.1 \pm 4.02^{*}$ & $11.6 \pm 3.34 \ddagger$ & & & \\
\hline OPCAB & $2.5 \pm 0.43$ & $9.1 \pm 1.09^{*}$ & $8.2 \pm 1.45^{*}$ & $7.9 \pm 0.79^{*}$ & $4.1 \pm 0.94 \ddagger$ & & & \\
\hline \multicolumn{6}{|c|}{$\mathrm{F} 1.2(\mathrm{nmol} / \mathrm{L}$, mean $\pm \mathrm{SEM})$} & $<.0001$ & .0043 & $<.0001$ \\
\hline CABG & $1.38 \pm 0.11$ & $4.80 \pm 0.37^{*} \dagger$ & $3.96 \pm 0.36^{*}$ & $3.44 \pm 0.22^{*}$ & $1.85 \pm 0.16 \ddagger$ & & & \\
\hline OPCAB & $1.20 \pm 0.12$ & $1.55 \pm 0.15$ & $2.64 \pm 0.22^{*}$ & $2.63 \pm 0.23^{*}$ & $1.64 \pm 0.16^{*}$ & & & \\
\hline \multicolumn{6}{|c|}{ Fibrinogen $(\mathrm{mg} / \mathrm{dL}$, mean $\pm \mathrm{SEM})$} & $<.0001$ & .71 & .69 \\
\hline CABG & $429 \pm 30.3$ & $307 \pm 23.7^{*}$ & $878 \pm 33.0^{*}$ & $788 \pm 26.3^{*}$ & $429 \pm 17.5$ & & & \\
\hline OРCAB & $393 \pm 16.9$ & $299 \pm 18.1^{*}$ & $844 \pm 43.1^{*}$ & $771 \pm 41.8^{*}$ & $385 \pm 14.2$ & & & \\
\hline \multicolumn{6}{|c|}{$\mathrm{XDP}(\mathrm{ng} / \mathrm{Ml}$, mean $\pm \mathrm{SEM})$} & .0419 & $<.0001$ & $<.0001$ \\
\hline CABG & $60 \pm 7.0$ & $1250 \pm 141.7^{*} \dagger$ & $682 \pm 105.6^{*} \S$ & $1247 \pm 145.4^{*} \dagger$ & $217 \pm 31.2^{*}$ & & & \\
\hline OPCAB & $54 \pm 8.2$ & $71 \pm 8.1$ & $314 \pm 51.0^{*}$ & $570 \pm 60.6^{*}$ & $118 \pm 22.1 \ddagger$ & & & \\
\hline \multicolumn{6}{|c|}{ vWF (U/mL, mean \pm SEM) } & $<.0001$ & $<.0001$ & .33 \\
\hline CABG & $25 \pm 2.8$ & $34 \pm 2.3^{*} \dagger$ & $56 \pm 3.4^{*} \dagger$ & $53 \pm 3.9^{*} \dagger$ & $25 \pm 2.5$ & & & \\
\hline OPCAB & $22 \pm 2.7$ & $21 \pm 2.5$ & $44 \pm 3.2^{*}$ & $37 \pm 3.4^{*}$ & $23 \pm 3.7$ & & & \\
\hline \multicolumn{6}{|c|}{ sVCAM $(\mathrm{ng} / \mathrm{mL}$, mean \pm SEM) } & .0439 & .18 & .23 \\
\hline CABG & $381 \pm 21.8$ & $373 \pm 19.5$ & $349 \pm 30.0$ & $469 \pm 42.6$ & $550 \pm 34.8^{*}$ & & & \\
\hline ОРСАВ & $402 \pm 27.0$ & $330 \pm 22.0$ & $352 \pm 21.6$ & $382 \pm 18.1$ & $494 \pm 36.3^{*}$ & & & \\
\hline
\end{tabular}

*Significant difference $(P<.01$, repeated measures ANCOVA) within each group as compared with baseline. $†$ Significant difference $(P<.01$, repeated measures ANCOVA) between CABG and OPCAB groups. $¥$ Significant difference $(P<.05$, repeated measures ANCOVA) within each group as compared with baseline. $\S$ Significant difference $(P<.05$, repeated measures ANCOVA) between CABG and OPCAB groups.

\section{CABG Surgery}

A nonpulsatile roller pump, hollow-fiber oxygenator with integrated heat exchanger, arterial filter, open cardiotomy reservoir, and polyvinyl tubing system was used in all cases. Each operation was performed with tepid hypothermia $\left(32^{\circ} \mathrm{C}-34^{\circ} \mathrm{C}\right)$ and hemodilution. Blood flow during CPB was maintained at $2.4 \mathrm{~L} /\left(\mathrm{min} \cdot \mathrm{m}^{2}\right)$, and hematocrit was kept at $18 \%$ to $25 \%$. Myocardial protection was achieved by the administration of cool $\left(4^{\circ} \mathrm{C}\right)$ multidose (every 15-20 minutes) blood cardioplegia (Buckberg solution) infused through the aortic root and the coronary sinus.

\section{OPCAB Surgery}

All OPCAB procedures were performed through midline sternotomy. Mechanical stability of the coronary arteriotomy area was achieved with the Octopus III system (Medtronic, Inc, Minneapolis, Minn), and a soft plastic coronary flow-shunt was always introduced into the coronary arteriotomy to maintain some degree of distal flow, to reduce myocardial ischemia, and to improve visualization of the anastomosis area. Coronary artery exposure was achieved with stay sutures applied on the left lateral side of pericardium or with deep pericardial stay sutures placed above the entry of the left lower pulmonary vein and laterally to the entry of the inferior vena cava.

\section{Follow-up}

All patients were hospitalized until postoperative day 8. Then all patients underwent a follow-up visit (physical examination, electrocardiogram, and blood collection) at postoperative day 30 .

\section{Blood Sampling}

Blood collection was performed from the antecubital vein through a 19-gauge needle in plastic tubes containing $0.13-\mathrm{mol} / \mathrm{L}$ sodium citrate (1/10 volume/volume) at baseline (the day before surgery), 5 minutes after protamine administration, at stable hemodynamic conditions, and at 4, 8, and 30 days after surgical intervention. Plasma was prepared by centrifugation at $1500 \mathrm{~g}$ for 20 minutes at $4{ }^{\circ} \mathrm{C}$ within 30 minutes from venipuncture, divided into aliquots, and frozen at $-80^{\circ} \mathrm{C}$ until assay.

Fibrinogen levels were measured according to Clauss ${ }^{11}$ (Fibrinogen-C; Instrumentational Laboratory, Milan, Italy) with a coagulometer (ACL 300; Instrumentational Laboratory). Thrombinantithrombin complex (TAT), D-dimer (XDP), prothrombin fragment F1.2 (F1.2), von Willebrand factor (vWF), and soluble vascular cell adhesion molecule 1 (sVCAM) levels were determined by enzyme-linked immunosorbent assay with commercially available kits, according to manufacturers' recommendations (Enzygnost TAT Dade Behring; Dimertest GOLD EIA Kit, AGEN Biomedical Limited; Enzygnost F1.2 Dade Behring; von Willebrand Factor ELISA Kit, Gradipore; Human Soluble VCAM-1 Immunoassay, R\&D Systems, Inc, Minneapolis, Minn). All data were normalized for hematocrit values.

\section{Statistical Analysis}

Continuous variables are presented as mean \pm SEM; categorical variables are presented as percentages. Group differences in clinical variables between $\mathrm{CABG}$ and $\mathrm{OPCAB}$ were assessed with Mann-Whitney, $\chi^{2}$, or Fisher exact tests as indicated. General linear model analysis of covariance (ANCOVA) models were used for statistical analysis of time, group (CABG vs OPCAB), and interaction (time*group) effects in coagulation, fibrinolytic, and endothelial activation variables. When time, group, or interaction effects were significant $(P<.05)$, repeated measures analysis of 

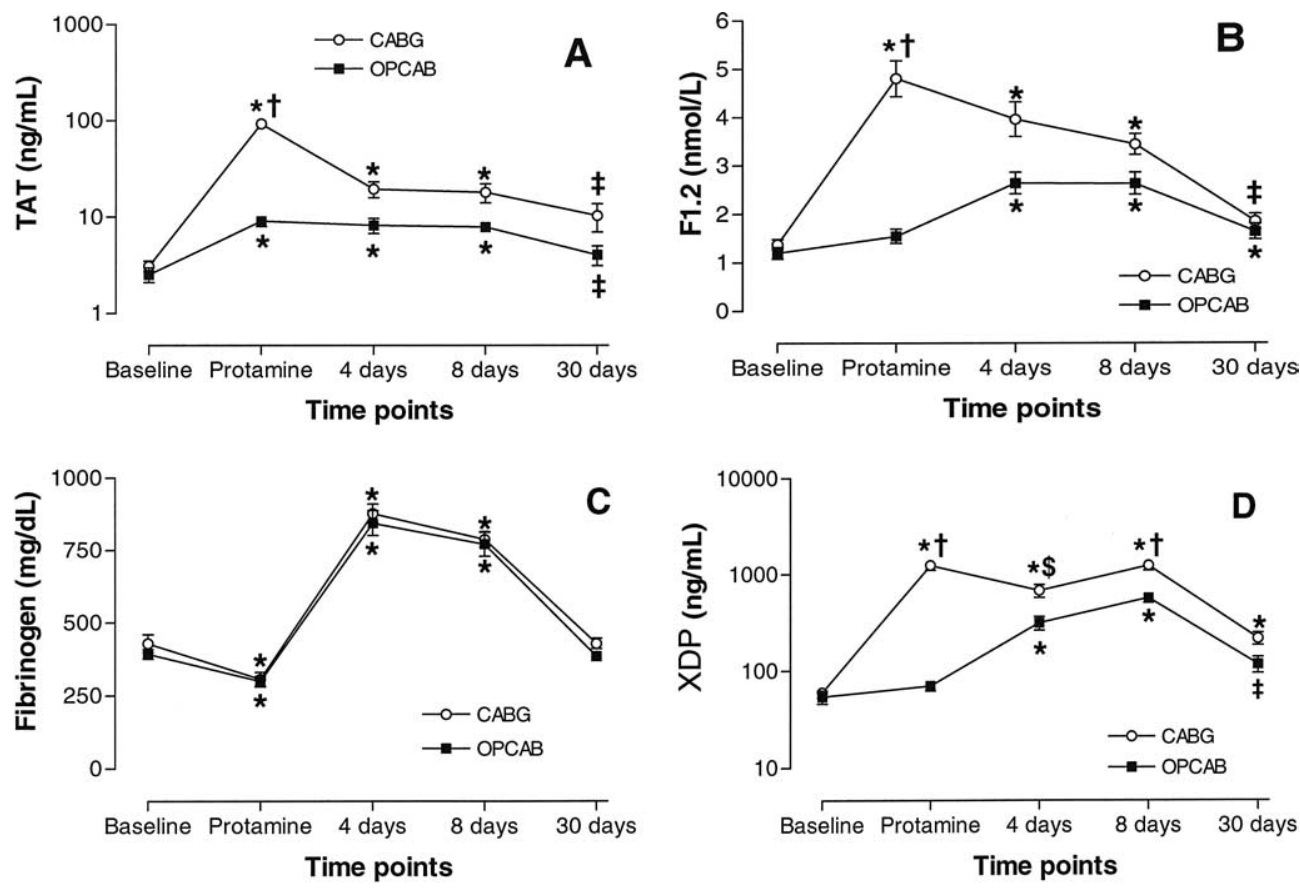

Figure 1. Plasma TAT (A), F1.2 (B), fibrinogen (C), and XDP (D) at each time interval. Data points represent mean; error bars indicate SEM. Empty circles indicate patients assigned to CABG $(n=18)$; filled squares indicate patients assigned to OPCAB ( $n=15)$. Note that $y$-axis is logarithmic in A and D. Asterisk indicates significant difference $(P<.01$ by repeated measures ANCOVA) within each group relative to baseline; dagger indicates significant difference $(P<.01$ by repeated measures ANCOVA) between CABG and OPCAB groups; double dagger indicates significant difference $(P<.05$ by repeated measures ANCOVA) within each group relative to baseline; dollar sign indicates significant difference $(P<.05$ by repeated measures ANCOVA) between CABG and OPCAB groups.

variance with Bonferroni correction was used to establish significant point-by-point differences.

\section{Results}

Thirty-three patients of the original 35 completed the study. Two patients in the OPCAB group were excluded: 1 because of excessive bleeding requiring reexploration and 1 because of refusal to participate in the study after random assignment. No significant differences in clinical variables were detected between patients randomly assigned to OPCAB versus CABG (Table 1). Red blood cells were transfused in 3 patients in the CABG group and 1 in the OPCAB group, whereas no plasma, platelet, or cryoprecipitate transfusions were needed (Table 1). Also, there were no differences at baseline between groups in coagulation, fibrinolytic, and endothelial activation variables (Table 2).

\section{Coagulation and Fibrinolysis Variables}

Persistent postoperative increases in plasma levels of TAT and F1.2 were observed in both groups relative to baseline; these persisted at 30 days (Figure $1, A$ and $B$, and Table 2). In the OPCAB group, the increase in TAT levels occurred earlier than that of F1.2, whereas the two variables simultaneously increased in patients undergoing CABG. Point-by-point analysis showed significant differences between OPCAB and CABG only after protamine, with F1.2 and TAT levels higher in the CABG group. Interestingly, a tendency toward an increase in plasma levels of tissue factor was found at 4 days after surgery in both groups (data not shown).

Fibrinogen significantly decreased in both OPCAB and CABG groups (Figure 1, $C$, and Table 2) after protamine but markedly increased at 4 and 8 postoperative days, reaching preoperative levels 30 days after surgery with no difference between the two groups.

After surgery, XDP significantly and persistently (to 30 days) increased in both groups, with a delay in the OPCAB group (at 4 days after surgery) relative to the $\mathrm{CABG}$ group (Figure 1, D, and Table 2). Point-by-point analysis showed that the levels of this marker were higher after CABG than after $\mathrm{OPCAB}$ starting from the protamine time point to 8 days after surgery.

\section{Plasma Markers of Endothelial Injury}

The behavior of endothelial injury differed from that of coagulation markers. The vWF level increased after surgery 
to 8 postoperative days in both groups but had returned to baseline levels at 30 days, with levels significantly higher in the CABG group (Figure 2, $A$, and Table 2). Finally, in both groups there was a significant effect of time $(P=.0439)$ for sVCAM, with a significant increase from baseline at 30 days after surgery, whereas no group effect was observed (Figure 2, B, and Table 2).

\section{Discussion}

This study shows that in patients undergoing OPCAB, a persistent activation of coagulation and of fibrinolytic pathways as well as of endothelium occurs and lasts as late as 30 days after surgery. Interestingly, in OPCAB these events are delayed relative to $\mathrm{CABG}$; in fact, after protamine administration the levels of F1.2 and XDP in the OPCAB group were comparable to those at baseline. Likewise, plasma vWF levels in the OPCAB group paralleled those of blood coagulation to 8 days after surgery, which suggests a delayed endothelial perturbation resolving within the 30 days of follow-up. On the other hand, sVCAM is unaffected in the first week after surgery, whereas its levels in plasma significantly increase 30 days after surgery. A member of the immunoglobulin family that supports the stable attachment of monocytes to arterial endothelium, sVCAM is an endothelial marker reflecting the occurrence of atherosclerosis. ${ }^{12}$ It has been proposed to have a pathogenetic role not only in early atherogenesis but also in the progression of advanced atherosclerotic plaques ${ }^{13}$; the increase in SVCAM observed at the latest time point in both groups suggests that activation of this marker occurs irrespective of the surgical strategy.

Taken together, these data suggest that the avoidance of extracorporeal circulation protects from the early appearance of a prothrombotic state. However, it does not prevent the increases in prothrombotic and endothelial injury markers that occur during the follow-up.

Previous studies in patients undergoing $\mathrm{CABG}$ have shown a marked activation of the coagulation-fibrinolytic system that lasted several weeks, probably accounting for the increased thrombotic complications that frequently occur during the postoperative period. ${ }^{2-5}$ Indeed, the early period after coronary surgery is characterized by the highest rates of myocardial infarction, cerebrovascular accident, and coronary bypass graft occlusion, all occurring within the early months after surgery. ${ }^{14}$ The information about the behavior of hemostatic and endothelial activation variables after OPCAB is still limited and is related only to the very early hours after surgery. Indeed, early after surgery a less marked reduction in platelet counts, higher plasminogen, and lower XDP levels relative to CABG were observed, but no difference between groups was detectable 24 hours later. ${ }^{15}$ Also, no significant differences in early (to 8 or 24 hours) postoperative levels of endothelial adhesion mole-
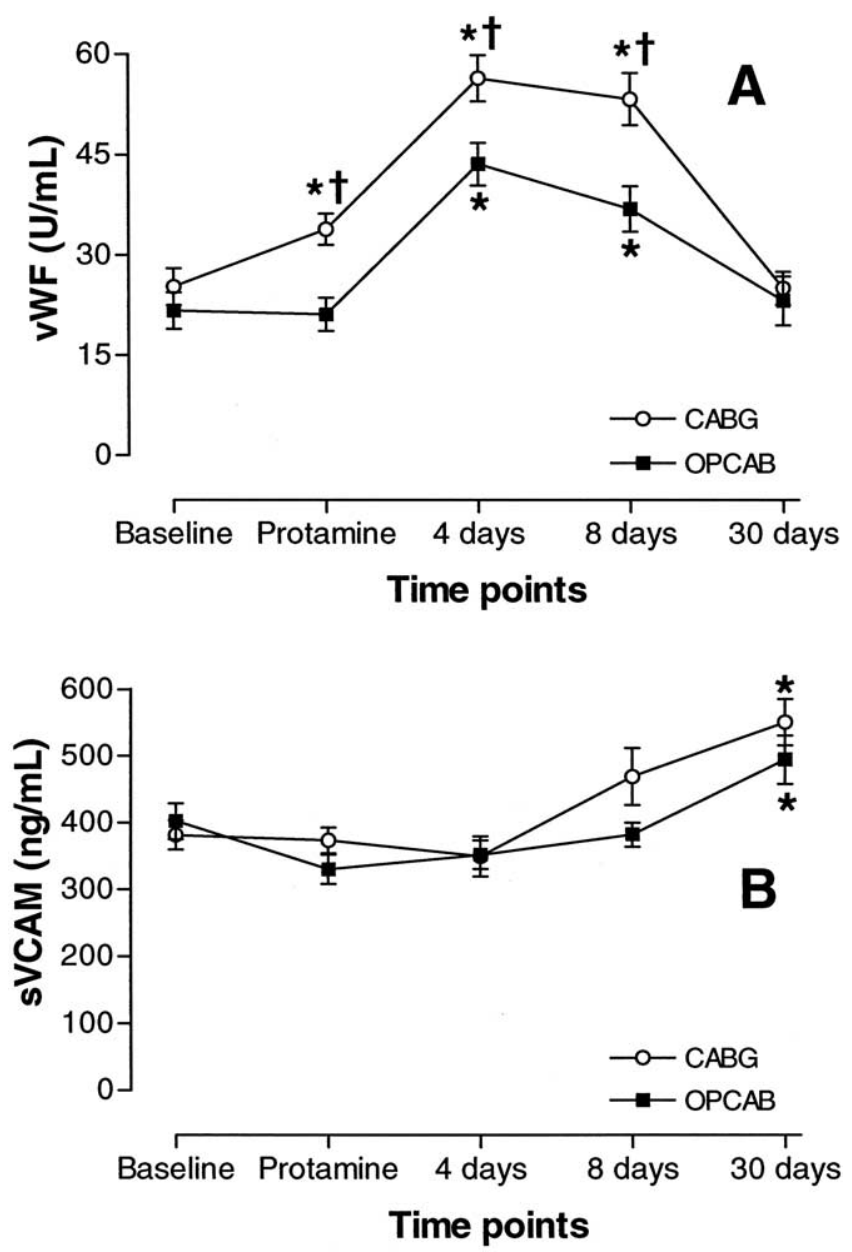

Figure 2. Plasma vWF (A) and sVCAM (B) at each time interval. Data points represent mean; error bars indicate SEM. Empty circles indicate patients assigned to CABG ( $n=18)$; filled squares indicate patients assigned to $\mathrm{OPCAB}(\mathrm{n}=15)$. Asterisk indicates significant difference $(P<.01$ by repeated measures ANCOVA) within each group relative to baseline; dagger indicates significant difference $(P<.01$ by repeated measures ANCOVA) between CABG and OPCAB groups.

cules, such as intracellular adhesion molecule 1 and Pselectin, or of endothelial cell activation markers have been reported. ${ }^{6,16}$

The analysis of the different activation patterns as seen after $\mathrm{CABG}$ and $\mathrm{OPCAB}$ allows us to distinguish two discrete phases: an early phase, occurring only after CABG, characterized by a sharp activation of coagulation and fibrinolysis, which may be ascribable to the use of extracorporeal circulation; and a later phase, occurring in patients undergoing either $\mathrm{CABG}$ or OPCAB, probably consequent to an inflammatory reaction induced by general surgical trauma. It has been hypothesized that OPCAB may result in greater risk of a prothrombotic state than $\mathrm{CABG}$ because of 
the lack of platelet stunning and the avoidance of coagulation factor consumption. ${ }^{17}$ In support of this hypothesis is the observation of early reduced patency rates of bypass grafts with this type of surgical approach. ${ }^{18}$ Our data indicate that the overall pattern of coagulation activation after OPCAB is significantly lower than that after CABG during the surgical intervention but similar to that after CABG during the follow-up.

Recently, it has been reported that platelet inhibition by aspirin is compromised within several days after CABG, probably because of an impaired interaction between aspirin and platelet cyclooxygenase. ${ }^{19}$ In this study, the behavior of platelets was not investigated, leaving open the question of whether a greater activation occurs during $\mathrm{OPCAB}$ or CABG.

Evidence concerning definitive clinical advantages of either technique of surgical myocardial revascularization is currently lacking, and the differences between OPCAB and CABG in terms of early clinical outcomes are so limited that very large randomized studies would be needed to ascertain the superiority of either technique. ${ }^{20}$ The modest activation of coagulation and fibrinolysis in OPCAB during surgery relative to $\mathrm{CABG}$ confirms and extends previous findings that document the protective effect of this surgical strategy against pro-oxidant, proinflammatory, and prothrombotic activation. During the midterm follow-up, whatever surgical strategy is adopted, a significant prothrombotic activation occurs and persists for several days or even weeks after surgery. This is accompanied by endothelial injury, as shown by postoperative increases in both groups of vWF, a glycoprotein synthesized by the endothelium and stored in Weibel-Palades bodies that is a selective marker of endothelial injury inflammatory vascular disease, ${ }^{21}$ and by a delayed proatherosclerotic atherogenic burden, as shown by the delayed increase of sVCAM levels 30 days after surgery. The data here reported, together with the evidence of platelet resistance to aspirin in patients undergoing CABG, raise the issue of the need of reevaluating antithrombotic treatment in both OPCAB and CABG.

The excellent technical assistance of Franco Moro is gratefully acknowledged.

\section{References}

1. Edmunds LH Jr. Inflammatory response to cardiopulmonary bypass. Ann Thorac Surg. 1998;66(5 Suppl):S12-6; discussion S25-8.

2. Parolari A, Colli S, Mussoni L, Eligini S, Naliato M, Wang X, et al. Coagulation and fibrinolytic markers in a two-month follow-up of coronary bypass surgery. J Thorac Cardiovasc Surg. 2003;125:336-43.
3. Mannucci L, Gerometta PS, Mussoni L, Antona C, Parolari A, Salvi L, et al. One month follow-up of haemostatic variables in patients undergoing aortocoronary bypass surgery. Effect of aprotinin. Thromb Haemost. 1995;73:356-61.

4. Moor E, Hamsten A, Blomback M, Herzfeld I, Wiman B, Ryden L. Hemostatic factors and inhibitors and coronary artery bypass grafting: preoperative alterations and relation to graft occlusion. Thromb Haemost. 1994;72:335-42.

5. Li N, Astudillo R, Ivert T, Hjemdahl P. Biphasic pro-thrombotic and inflammatory responses after coronary artery bypass surgery. $J$ Thromb Haemost. 2003;1:470-6.

6. Matata BM, Sosnowski AW, Galinanes M. Off-pump bypass graft operation significantly reduces oxidative stress and inflammation. Ann Thorac Surg. 2000;69:785-91.

7. Parolari A, Alamanni F, Cannata A, Naliato M, Bonati L, Rubini P, et al. OPCAB vs. CABG: meta-analysis of currently available randomized trials. Ann Thorac Surg. 2003;76:37-40.

8. Sabik JF, Gillinov AM, Blackstone EH, Vacha C, Houghtaling PL, Navia J, et al. Does off-pump coronary surgery reduce morbidity and mortality? J Thorac Cardiovasc Surg. 2002;124:698-707.

9. Biglioli P, Cannata A, Alamanni F, Naliato M, Porqueddu M, Zanobini $\mathrm{M}$, et al. Biological effects of off-pump vs. on-pump coronary artery surgery: focus on inflammation, hemostasis and oxidative stress. Eur J Cardiothorac Surg. 2003;24:260-9.

10. Eagle KA, Guyton RA, Davidoff R, Ewy GA, Fonger J, Gardner TJ, et al. ACC/AHA guidelines for coronary artery bypass graft surgery: executive summary and recommendations: A report of the American College of Cardiology/American Heart Association Task Force on Practice Guidelines (Committee to revise the 1991 guidelines for coronary artery bypass graft surgery). Circulation. 1999;100:1464-80.

11. Clauss A. Gerinnungsphysiologische Schnell-Methode zur Bestimmung des fibrinogens. Acta Haematol. 1957;17:237-46.

12. De Caterina R, Basta G, Lazzerini G, Dell'Omo G, Petrucci R, Morale $\mathrm{M}$, et al. Soluble vascular cell adhesion molecule-1 as a biohumoral correlate of atherosclerosis. Arterioscler Thromb Vasc Biol. 1997;17: 2646-54.

13. O'Brien KD, Allen MD, McDonald TO, Chait A, Harlan JM, Fishbein $\mathrm{D}$, et al. Vascular cell adhesion molecule-1 is expressed in human coronary atherosclerotic plaques. Implications for the mode of progression of advanced coronary atherosclerosis. J Clin Invest. 1993;92: 945-51.

14. Laffey JG, Boylan JF, Cheng DC. The systemic inflammatory response to cardiac surgery: implications for the anaesthesiologist. Anesthesiology. 2002;97:215-52.

15. Casati V, Gerli C, Franco A, Della Valle P, Benussi S, Alfieri O, et al. Activation of coagulation and fibrinolysis during coronary surgery: onpump versus off-pump techniques. Anesthesiology. 2001;95:1103-9.

16. Czerny M, Baumer H, Kilo J, Lassnigg A, Hamwi A, Vukovich T, et al. Inflammatory response and myocardial injury following coronary artery bypass grafting with or without cardiopulmonary bypass. Eur J Cardiothorac Surg. 2000;17:737-42.

17. Kurlansky PA. Is there a hypercoagulable state after off-pump coronary artery surgery? What do we know and what can we do? J Thorac Cardiovasc Surg. 2003;126:7-10.

18. Khan NE, De Souza A, Mister R, Flather M, Clague J, Davies S, et al. A randomized comparison of off-pump and on-pump multivessel coronary-artery bypass surgery. $N$ Engl J Med. 2004;350:21-8.

19. Zimmermann N, Wenk A, Kim U, Kienzle P, Weber AA, Gams E, et al. Functional and biochemical evaluation of platelet aspirin resistance after coronary artery bypass surgery. Circulation. 2003;108:542-7.

20. Parolari A, Biglioli P, Alamanni F. Improved early outcomes after OPCAB: when will the final answer come? [letter] Circulation. 2004; 109:e181.

21. Blann AD. von Willebrand factor as a marker of injury to the endothelium in inflammatory vascular disease. J Rheumatol. 1993;20:1469-71. 